\title{
Hemodynamic parameters to guide fluid therapy
}

\author{
Paul E Marik ${ }^{1 *}$, Xavier Monnet ${ }^{2}$, Jean-Louis Teboul ${ }^{2}$
}

\begin{abstract}
The clinical determination of the intravascular volume can be extremely difficult in critically ill and injured patients as well as those undergoing major surgery. This is problematic because fluid loading is considered the first step in the resuscitation of hemodynamically unstable patients. Yet, multiple studies have demonstrated that only approximately $50 \%$ of hemodynamically unstable patients in the intensive care unit and operating room respond to a fluid challenge. Whereas under-resuscitation results in inadequate organ perfusion, accumulating data suggest that over-resuscitation increases the morbidity and mortality of critically ill patients. Cardiac filling pressures, including the central venous pressure and pulmonary artery occlusion pressure, have been traditionally used to guide fluid management. However, studies performed during the past 30 years have demonstrated that cardiac filling pressures are unable to predict fluid responsiveness. During the past decade, a number of dynamic tests of volume responsiveness have been reported. These tests dynamically monitor the change in stroke volume after a maneuver that increases or decreases venous return (preload) and challenges the patients' Frank-Starling curve. These dynamic tests use the change in stroke volume during mechanical ventilation or after a passive leg raising maneuver to assess fluid responsiveness. The stroke volume is measured continuously and in real-time by minimally invasive or noninvasive technologies, including Doppler methods, pulse contour analysis, and bioreactance.
\end{abstract}

\section{Introduction}

The cornerstone of treating patients with shock remains as it has for decades: intravenous fluids. Surprisingly, dosing intravenous fluid during resuscitation of shock remains largely empirical. Too little fluid may result in tissue hypoperfusion and worsen organ dysfunction; however, over-prescription of fluid also appears to impede oxygen delivery and compromise patient outcome. Recent data suggest that early aggressive resuscitation of critically ill patients may limit and/or reverse tissue hypoxia, progression to organ failure, and improve outcome [1]. In a landmark study, Rivers et al. demonstrated that a protocol of early goal-directed therapy reduces organ failure and improves survival in patients with severe sepsis and septic shock [2]. Similarly, a protocol to optimize preload and cardiac output in patients undergoing major surgery reduced postoperative complications and length of stay [3]. Uncorrected hypovolemia, leading to inappropriate infusions of vasopressor agents may increase organ hypoperfusion and ischemia [4].

\footnotetext{
* Correspondence: marikpe@evms.edu

'Department of Medicine, Division of Pulmonary and Critical Care Medicine, Eastern Virginia Medical School, Norfolk, VA, USA.

Full list of author information is available at the end of the article
}

However, overzealous fluid resuscitation has been associated with increased complications, increased length of intensive care unit (ICU) and hospital stay, and increased mortality. A review of the ARDSNet cohort demonstrated a clear positive association between the mean cumulative daily fluid balance and mortality [5]. Murphy and colleagues demonstrated a similar finding in patients with septic shock [6]. Data from the "VAsopressin in Septic Shock Trial" demonstrated that the quartile of patients with the highest fluid balance at both 12 hours and 4 days had the highest adjusted mortality [7]. The extravascular lung water index (EVLWI) can be accurately "measured" in critically ill patients by using the single indicator transpulmonary thermodilution method) [8,9]. The EVLWI appears to be a useful tool to quantify "capillary leakiness" and the degree of interstitial edema [10]. A number of authors have demonstrated a positive relationship between EVLWI and mortality in critically ill patients $[11,12]$.

The first step in the hemodynamic management of critically ill patients is to determine the adequacy of tissue/organ perfusion. Although the signs of shock may be obvious, those of subclinical hypoperfusion may be more subtle (Table 1). It should be noted that increasing

\section{SpringerOpen ${ }^{\circ}$}

(C) 2011 Marik et al; licensee Springer. This is an Open Access article distributed under the terms of the Creative Commons Attribution License (http://creativecommons.org/licenses/by/2.0), which permits unrestricted use, distribution, and reproduction in any medium, provided the original work is properly cited. 


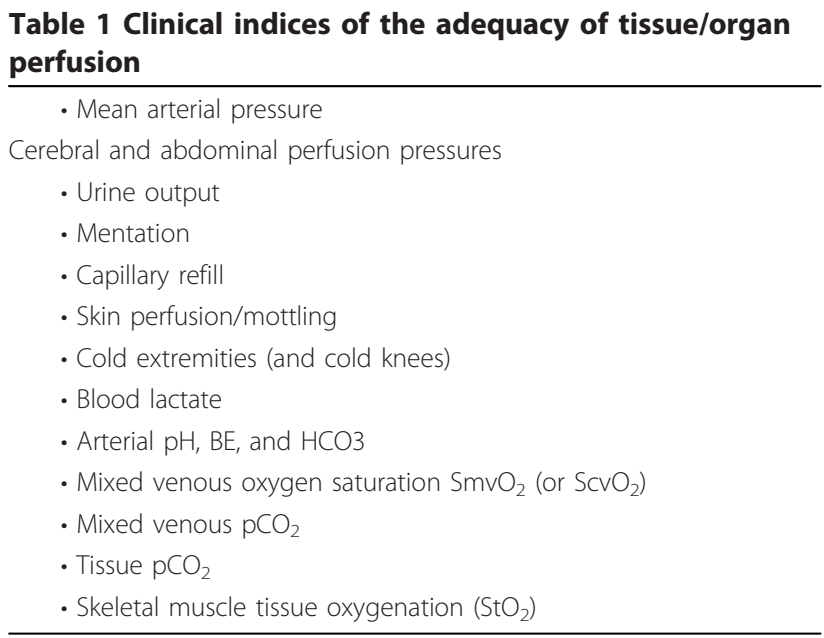

cardiac output/oxygen delivery in patients with adequate organ perfusion serves no useful purpose. Indeed, studies of yesteryear have demonstrated that targeting "supra-normal" hemodynamic parameters may be harmful $[13,14]$. In those patients with indices of inadequate tissue perfusion, fluid resuscitation is generally regarded as the first step in resuscitation. Clinical studies have, however, demonstrated that only approximately $50 \%$ of hemodynamically unstable critically ill patients are volume-responsive [15]. The resuscitation of the critically ill patient requires an accurate assessment of the patient's intravascular volume status (cardiac preload) and the likelihood that the patient will respond (increase stroke volume) to a fluid challenge (volume responsiveness). Patients with overt shock and those with subclinical shock and who are fluid-responsive are best managed by 500 to $1,000 \mathrm{~mL}$ boluses of fluid. Fluid boluses should be discontinued once the patient is no longer fluid-responsive or the EVLWI has increased significantly.

Fundamentally, the only reason to give a patient a fluid challenge is to increase stroke volume (volume responsiveness). If the fluid challenge does not increase stroke volume, volume loading serves the patient no useful benefit (may be harmful). According to the Frank-Starling principle, as the preload increases left ventricular (LV) stroke volume increases until the optimal preload is achieved at which point the stroke volume remains relatively constant (Figure 1 ). This optimal preload is related to the maximal overlap of the actin-myosin myofibrils. It is important to note that in an intact heart the actin-myosin links cannot be disengaged and hence there is no descending limb of the Frank-Starling curve. Once the left ventricle is functioning near the "flat" part of the Frank-Starling curve, fluid loading has little effect on the stroke volume. In normal physiologic conditions, both ventricles operate on the ascending portion of the Frank-Starling curve [16]. This mechanism provides a functional reserve to the heart in situations of acute stress. In normal individuals, an increase in preload (with volume challenge) results in a significant increase in stroke volume [17] (Figure 1).

Traditionally the central venous pressure (CVP) has been used to guide fluid management. A European survey of intensivists/anesthesiologists reported that more than 90\% used the CVP to guide fluid management [18]. A Canadian survey reported that $90 \%$ of intensivists use the CVP to monitor fluid resuscitation in patients with septic shock [19]. The basis for using the CVP to guide fluid management comes from the misguided dogma that the CVP reflects intravascular volume; specifically, it is widely believed that patients with a low CVP are volumedepleted, whereas patients with a high CVP are volumeoverloaded. Furthermore, the "5-2" rule, which was popularized in the $1970 \mathrm{~s}$ [20], is still widely used today for guiding fluid therapy. According to this rule, the change in CVP after a fluid challenge is used to guide subsequent fluid management decisions. The CVP is a good approximation of right atrial pressure, which is a major determinant of right ventricular (RV) filling. It has been assumed that the CVP is a good indicator of RV preload. Furthermore, because RV stroke volume determines LV filling, the CVP is assumed to be an indirect measure of LV preload. However, due to the changes in venous tone, intrathoracic pressures, LV and RV compliance, and geometry that occur in critically ill patients, there is a poor relationship between the CVP and RV end-diastolic volume. Furthermore, the RV end-diastolic volume may not reflect the patients' position on the Frank-Starling curve and therefore his/her preload reserve. More than 100 studies have been published to date that have demonstrated no relationship between the CVP (or change in CVP) and fluid responsiveness in various clinical settings [21]. Indeed, there have only been two studies published in the world literature that demonstrate "some relationship" between the CVP and intravascular volume; both of these studies were conducted in standing horses [22,23]! Based on this information, we believe that the CVP should no longer be routinely used for guiding fluid management in the ICU, operating room, or emergency room.

Until recently, it has been unclear as to which hemodynamically unstable patients are volume-responsive and likely to benefit from fluid resuscitation (fluid boluses). However, during the past decade a number of dynamic tests of volume responsiveness have been reported. These tests dynamically monitor the change in stroke volume after a maneuver that increases or decreases venous return (preload). These tests allow the clinician to determine the individual patient's position on his/her Frank-Starling curve, and thus determine whether the patient is likely to be fluid-responsive. These techniques 


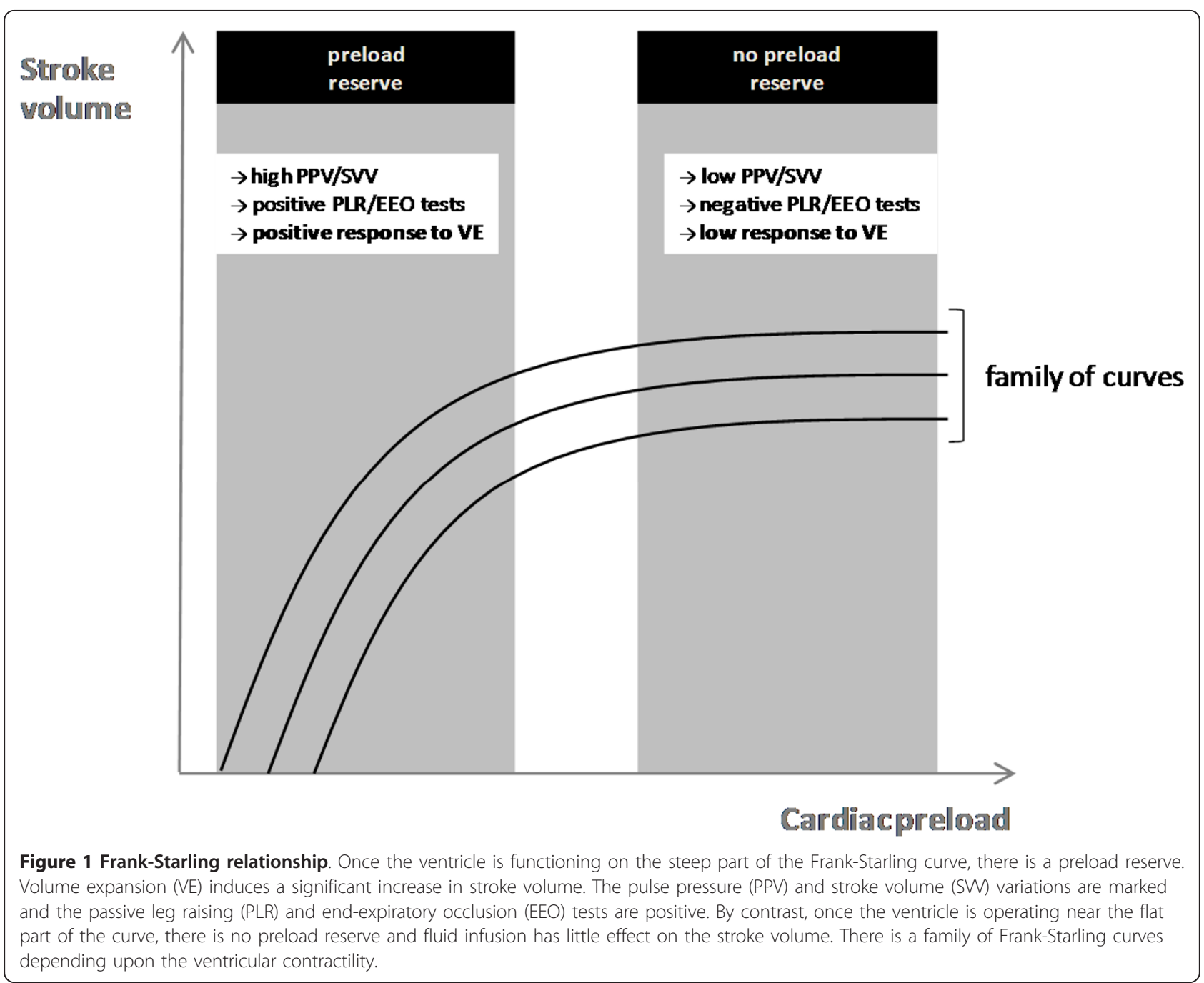

use the change in stroke volume during mechanical ventilation or after a passive leg raising (PLR) maneuver to assess fluid responsiveness.

\section{Heart-lung interactions during mechanical ventilation}

Dynamic changes in stroke volume, pulse pressure, and oximetric waveform

An impressive number of studies have demonstrated that the pulse pressure variation (PPV) derived from analysis of the arterial waveform, the stroke volume variation (SVV) derived from pulse contour analysis, and the variation of the amplitude of the pulse oximeter plethysmographic waveform to be highly predictive of fluid responsiveness [15]. The principles underling this technique are based on simple physiology (Figure 2). Intermittent positive-pressure ventilation induces cyclic changes in the loading conditions of the left and right ventricles. Mechanical insufflation decreases preload and increases afterload of the right ventricle. The RV preload reduction is due to the decrease in the venous return pressure gradient that is related in the inspiratory increase in pleural pressure [24]. The increase in RV afterload is related to the inspiratory increase in transpulmonary pressure. The reduction in RV preload and increase in RV afterload both lead to a decrease in RV stroke volume, which is at a minimum at the end of the inspiratory period [25]. The inspiratory reduction in RV ejection leads to a decrease in LV filling after a phase lag of two or three heart beats because of the long blood pulmonary transit time. Thus, the LV preload reduction may induce a decrease in LV stroke volume, which is at its minimum during the expiratory period when conventional mechanical ventilation is used. The cyclic changes in RV and LV stroke volume are greater when the ventricles operate on the steep rather than the flat portion of the Frank-Starling curve (Figure 1). The magnitude of the respiratory changes in LV stroke 


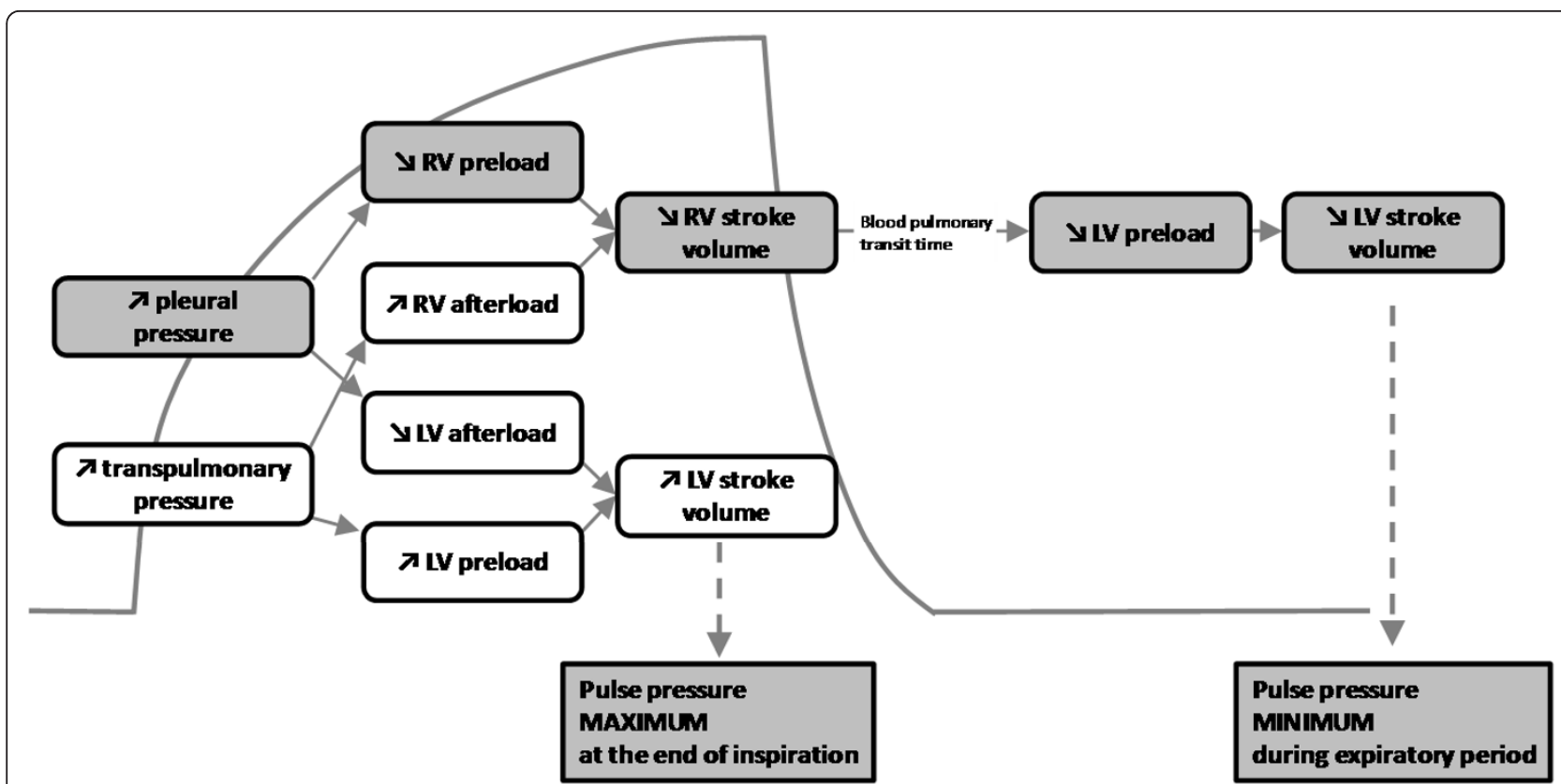

Figure 2 Heart-lung interactions. Hemodynamic effects of mechanical ventilation. The cyclic changes in left ventricular (LV) stroke volume are mainly related to the expiratory decrease in LV preload due to the inspiratory decrease in right ventricular (RV) filling. Reproduced with permission from Critical Care/Current Science Ltd [24].

volume is an indicator of biventricular preload dependence [24]. With remarkable consistency, a variation of greater than $12 \%$ to $13 \%$ has been reported to be highly predictive of volume responsiveness (Table 2) [15].

The pulse oximeter plethysmographic waveform differs from the arterial pressure waveform by measuring volume rather than pressure changes in both arterial and venous vessels. As an extension of pulse pressure analysis during mechanical ventilation, dynamic changes in both the peak and amplitude of the pulse oximeter plethysmographic waveform have been used to predict fluid responsiveness [26]. The dynamic changes of the plethysmographic waveform with positive pressure ventilation have shown a significant correlation and good agreement with the PPV and have accurately predicted fluid responsiveness in both the operating room and ICU setting [27-29]. The "Pleth Variability Index" (PVI) is an automated measure of the dynamic change in the "Perfusion Index" that occurs during a respiratory cycle (Masimo Corporation, Irvine, CA).
The "Perfusion Index" is the infrared pulsatile signal indexed against the nonpulsatile signal and reflects the amplitude of the pulse oximeter waveform. The PVI correlates closely with the respiratory induced variation in the plethysmographic and arterial pressure waveforms and can predict fluid responsiveness noninvasively in mechanically ventilated patients $[30,31]$. These oximetric techniques may be valuable for monitoring fluid responsiveness in ICU and surgical patients who do not have an arterial catheter in situ.

It should be appreciated that both arrhythmias and spontaneous breathing activity will lead to misinterpretations of the respiratory variations in pulse pressure/ stroke volume. Furthermore, for any specific preload condition the PPV/SVV will vary according to the tidal volume. Reuter and colleagues demonstrated a linear relationship between tidal volume and SVV [32]. De Backer and colleagues evaluated the influence of tidal volume on the ability of the PPV to predict fluid

Table 2 Predictive value of techniques used to determine fluid responsiveness [15]

\begin{tabular}{lll}
\hline Method & Technology & AUC* \\
\hline Pulse pressure variation (PPV) & Arterial waveform & $0.94(0.93-0.95)$ \\
Systolic pressure variation (SPV) & Arterial waveform & $0.86(0.82-0.90)$ \\
Stroke volume variation (SW) & Pulse contour analysis & $0.84(0.78-0.88)$ \\
Left ventricular end-diastolic area (LVEDA) & Echocardiography & $0.64(0.53-0.74)$ \\
Global end-diastolic volume (GEDV) & Transpulmonary thermodilution & $0.56(0.37-0.67)$ \\
Central venous pressure (CVP) & Central venous catheter & $0.55(0.48-0.62)$ \\
\hline
\end{tabular}

${ }^{*}$ AUC $=$ area under the curve with $95 \%$ confidence intervals. 
responsiveness [33]. These authors reported that the PPV was a reliable predictor of fluid responsiveness only when the tidal volume was at least $8 \mathrm{~mL} / \mathrm{kg}$. For accuracy, reproducibility, and consistency we suggest that the tidal volume be increased to 8 to $10 \mathrm{~mL} / \mathrm{kg}$ ideal body weight before and after a fluid challenge.

\section{Dynamic changes in aortic flow velocity/stroke volume assessed by Doppler methods}

The respiratory changes in aortic flow velocity and stroke volume can be assessed by Doppler echocardiography. Assuming that the aortic annulus diameter is constant over the respiratory cycle, the changes in aortic blood velocity should reflect changes in LV stroke volume. Feissel and colleagues demonstrated that the respiratory changes in aortic blood velocity as measured by transesophageal echocardiography predicted fluid responsiveness in mechanically ventilated patients [34]. Similarly, ventilator-induced variation in descending aortic blood flow measured by esophageal Doppler monitoring has been demonstrated to predict fluid responsiveness [35].

\section{Positive pressure ventilation induced changes in vena- caval diameter}

Cyclic changes in superior and inferior vena-caval diameter as measured by echocardiography have been used to predict fluid responsiveness. Barbier and colleagues and Feissel and coworkers demonstrated that the distensibility index of the inferior vena cava, which reflects the increase in the inferior vena cava diameter on inspiration (mechanical ventilation), was able to predict fluid responsiveness [36,37]. Similarly, Vieillard-Baron and colleagues have demonstrated that the collapsibility index of the superior vena cava is highly predictive of volume responsiveness $[38,39]$. Both of these techniques are not conducive to continuous monitoring. Furthermore, the superior vena cava can only be adequately visualized by transesophageal echocardiography.

\section{The end-expiratory occlusion test}

During mechanical ventilation, each insufflation increases intrathoracic pressure and thus reduces the systemic venous return. In a recent study, it was hypothesized that interrupting mechanical insufflation during an end-expiratory occlusion can increase cardiac preload sufficiently for such a test being used to predict fluid responsiveness [40] (Figure 3). This study included 34 patients who received mechanical ventilation. Patients had cardiac arrhythmias or exhibited a certain degree of spontaneous breathing activity not sufficient to interrupt the brief (15 seconds) end-expiratory occlusion of the respiratory circuit. In patients who will

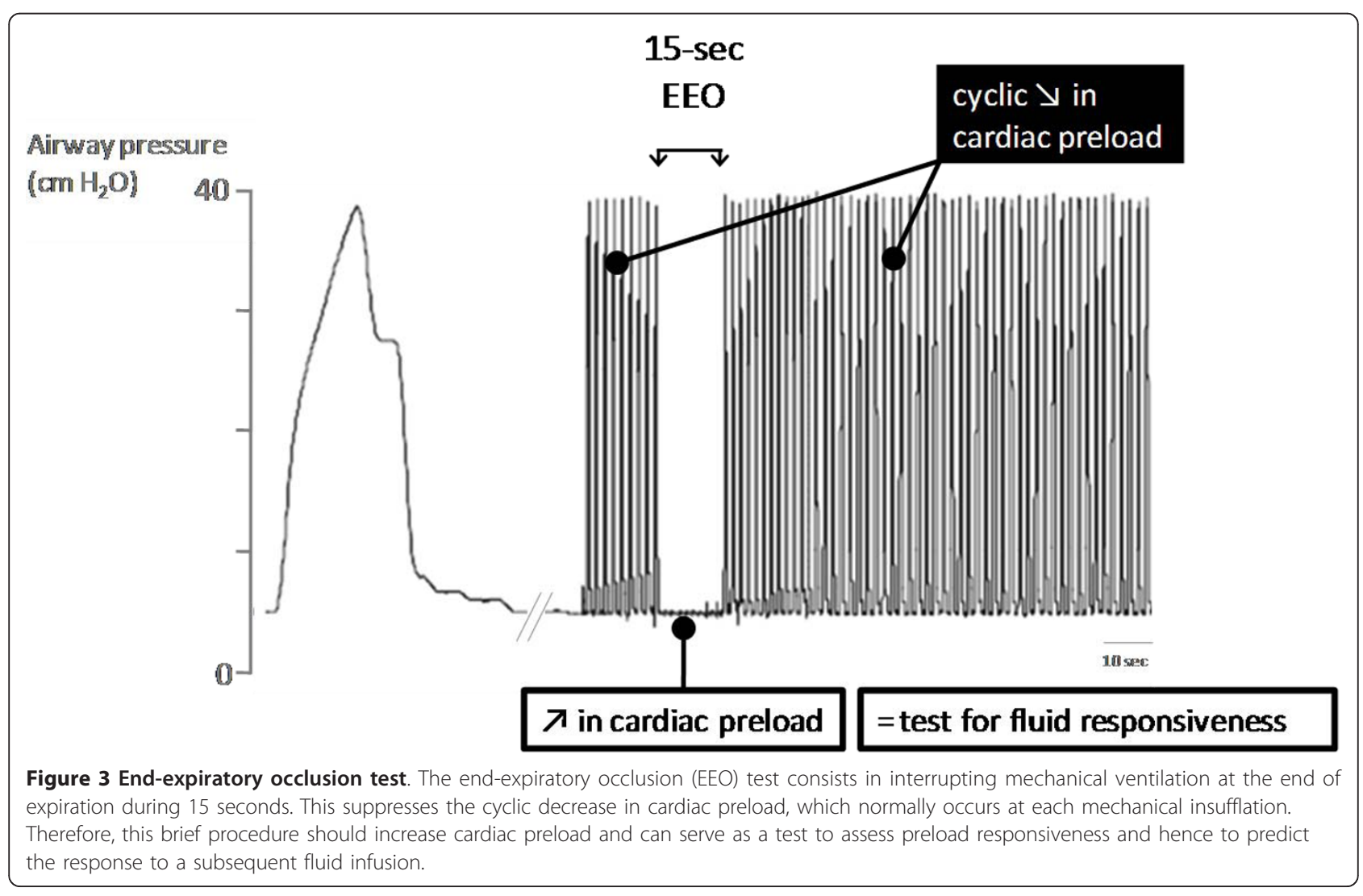


increase their cardiac output by more than $15 \%$ in response to a subsequent $500-\mathrm{mL}$ fluid challenge (fluid responders), the end-expiratory occlusion test increased both arterial pulse pressure and pulse contour cardiac output [40]. In nonresponder patients, the end-expiratory occlusion test did not induce a significant increase in pulse pressure and cardiac output. An increase in cardiac output and arterial pulse pressure by more than $5 \%$ predicted fluid responsiveness with a good accuracy. This test is easy to use in clinical practice and seems to be reliable in cases of cardiac arrhythmias and of low tidal volume, conditions where PPV and SVV are unreliable [X Monnet and JL Teboul, personal observations].

\section{Passive leg raising}

In the initial stages of resuscitation in the emergency room, ward, or ICU, most patients are not intubated and are breathing spontaneously. In addition, with the reduced use of sedative agents in the ICU, many critically ill patients are ventilated with modes of ventilation that allow spontaneous breathing activity. Because the respiratory variability of hemodynamic signals cannot be used for predicting volume responsiveness in spontaneously breathing patients, other techniques, such as passive leg raising (PLR), have been proposed for this purpose $[41,42]$. Lifting the legs passively from the horizontal position induces a gravitational transfer of blood from the lower limbs toward the intrathoracic compartment (Figure 4). Accordingly, increases in the pulmonary artery occlusion pressure and the LV ejection time [43] have been reported during PLR, supporting the evidence that the volume of blood transferred to the heart during PLR is sufficient to increase the left cardiac preload and thus challenge the Frank-Starling curve. Beyond its ease of use, this method has the advantage of reversing its effects once the legs are tilted down $[43,44]$. Therefore, PLR may be considered a reversible "autotransfusion."

The concept of detecting preload responsiveness by using PLR emerged from a study in mechanically ventilated patients, where the increase in thermodilution stroke volume after a fluid infusion correlated with the increase in arterial pulse pressure produced by PLR [44]. The ability of PLR to serve as a test of preload responsiveness has been confirmed in additional studies performed in critically ill patients [40,43,45-51]. The change in aortic blood flow (measured by esophageal Doppler) during a $45^{\circ}$ leg elevation was shown to predict the changes in aortic blood flow produced by a 500-mL fluid challenge even in patients with cardiac arrhythmias and/or spontaneous ventilator triggering, situations in which PPV lost its predictive ability [43]. A recent meta-analysis, which pooled the results of eight recent studies, confirmed the excellent value of PLR to predict fluid responsiveness in critically ill patients with a global area under the receiver operating characteristic curve of 0.95 [51]. The best way to perform a PLR maneuver to predict volume responsiveness is to elevate the lower limbs to $45^{\circ}$ (automatic bed elevation or wedge pillow) while at the same time placing the patient in the supine from a $45^{\circ}$ semirecumbent position (Figure 4). Starting the PLR maneuver from a total

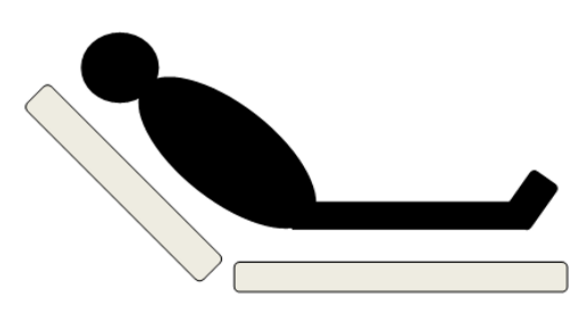

Figure 4 Passive leg raising. The passive leg raising test consists in measuring the hemodynamic effects of a leg elevation up to $45^{\circ}$. A simple way to perform the postural maneuver is to transfer the patient from the semirecumbent posture to the passive leg raising position by using the automatic motion of the bed.

passive leg raising

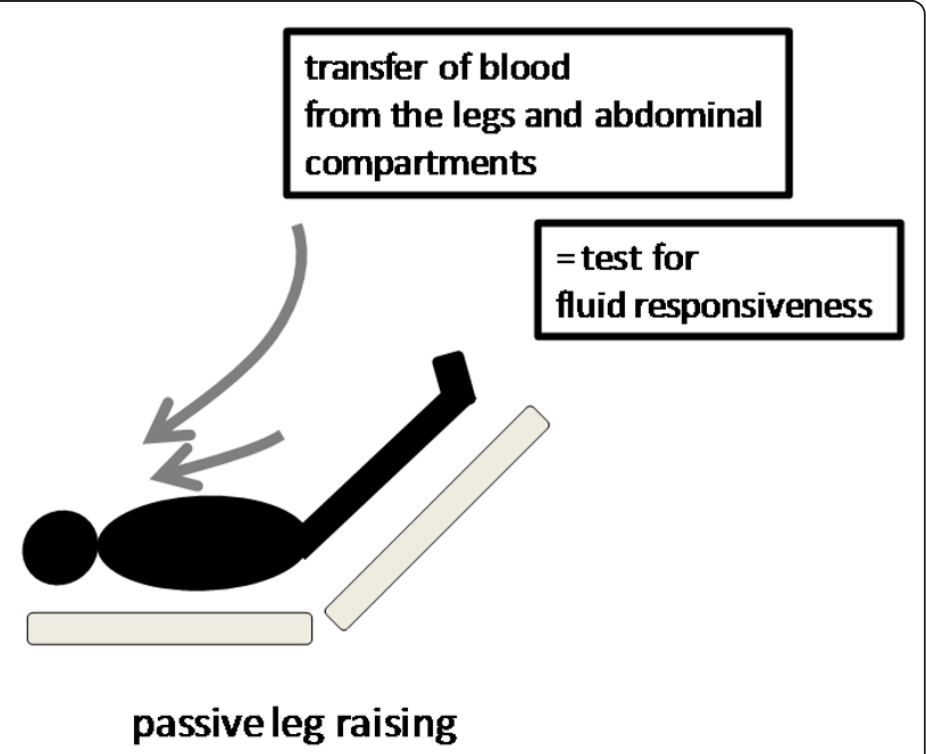


horizontal position may induce an insufficient venous blood shift to elevate significantly cardiac preload [52]. By contrast, starting PLR from a semirecumbent position induces a larger increase in cardiac preload because it induces the shift of venous blood not only from both the legs but also from the abdominal compartment [53]. In should be noted that intra-abdominal hypertension (intra-abdominal pressure $>16 \mathrm{mmHg}$ ) impairs venous return and reduces the ability of PLR to detect fluid responsiveness [54].

Because the maximal hemodynamic effects of PLR occur within the first minute of leg elevation [43], it is important to assess these effects with a method that is able to track changes in cardiac output or stroke volume on a real-time basis. In this regard, the response of descending aortic blood flow (measured by esophageal Doppler) to PLR $[43,45]$, of the velocity-time integral (measured by transthoracic echocardiography) [46,47], and the femoral artery flow (measured by arterial Doppler) [50] to PLR have been demonstrated to be helpful in predicting the response to volume administration in patients with spontaneous breathing activity. Echocardiographic techniques are, however, operator-dependent and not conducive to continuous real-time monitoring. Until recently, continuous real-time cardiac output monitoring required a thermodilution pulmonary artery catheter. During the past decade, several less invasive methods have been developed. These techniques include transpulmonary thermodilution, pulse-contour analysis, and bioreactance. The PiCCO ${ }^{\mathrm{TM}}$ system (Pulsion Medical Systems, Munich, Germany) uses transpulmonary thermodilution to calibrate the pulse-contour-derived stroke volume, whereas the stroke volume derived from the FloTrac-Vigileo ${ }^{\mathrm{TM}}$ (Edward Lifesciences, Irvine, CA) device is uncalibrated. Both of these devices may be useful to determine the hemodynamic response to PLR. In this regard, an increase in "pulse contour" cardiac output by more than $10 \%$ in response to PLR has been shown to accurately predict volume responsiveness in mechanically ventilated patients with spontaneous breathing activity $[40,48]$. Although less invasive than pulmonary artery catheterization, these techniques are not ideally suited to resuscitation in the emergency room or ward or on initial presentation in the ICU. In these situations, the change in stoke volume after a PLR maneuver can be assessed noninvasively by bioreactance. Bioreactance cardiac output measurement is based on an analysis of relative phase shifts of an oscillating current that occurs when this current traverses the thoracic cavity. It differs from traditional bioimpedance-based systems, which rely on measured changes in signal amplitude [55]. The NICOM ${ }^{\mathrm{TM}}$ (Cheetah Medical, Portland, OR, USA) is comprised of a high-frequency $(75 \mathrm{kHz})$ sine wave generator and four dual electrode "stickers" that are used to establish electrical contact with the body. The cardiac output as measured by bioreactance has been shown to be highly correlated with that measured by thermodilution and pulse contour analysis [55-57]. In a cohort of patients after elective cardiac surgery, Benomar and coauthors demonstrated that the NICOM ${ }^{\mathrm{TM}}$ system could accurately predict fluid responsiveness from changes in cardiac output during PLR [58]. The NICOM ${ }^{\mathrm{TM}}$ system has an algorithm with user prompts and an interface that rapidly facilitates the performance of a PLR maneuver.

Although the dynamic changes of the plethysmographic waveform have been demonstrated to be predictive of volume responsiveness in ventilated patients, this technology is poorly predictive of volume responsiveness in spontaneously breathing persons after a PLR challenge [59]. The hemodynamic effects of PLR must be assessed by a direct measure of cardiac output or stroke volume; assessing the PLR effects solely on the arterial pulse pressure leads to a significant number of falsenegative cases [51]. This suggests that in spontaneously breathing patients, pulse pressure is not of sufficient sensitivity for detecting changes in stroke volume.

\section{Conclusions}

A number of minimally invasive and noninvasive diagnostic tools are currently available that allow clinicians to assess volume responsiveness using dynamic procedures that challenge the patients' Frank-Starling curve. These technologies complement one another; each has a useful place in the continuum of the resuscitation process.

\section{Author details}

'Department of Medicine, Division of Pulmonary and Critical Care Medicine, Eastern Virginia Medical School, Norfolk, VA, USA. ${ }^{2}$ Medical Intensive Care Unit, Research Unit EA 4046, Bicetre Teaching Hospital, Paris-11 University, Le Kremlin-Bicetre, France.

\section{Authors' contributions}

PEM, XM, and JLT contributed to draft the manuscript and approved the final version.

\section{Competing interests}

Paul E. Marik has no financial interest in any of the products mentioned in this paper. Xavier Monnet and Jean-Louis Teboul are members of the medical advisory board of Pulsion Medical Systems.

Received: 24 January 2011 Accepted: 21 March 2011

Published: 21 March 2011

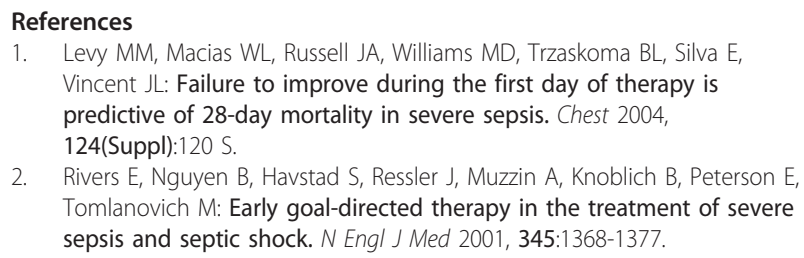


3. Lopes MR, Oliveira MA, Pereira VO, Lemos IP, Auler JO Jr, Michard F, Michard F: Goal-directed fluid management based on pulse pressure variation monitoring during high-risk surgery: a pilot randomized controlled trial. Crit Care 2007, 11:R100.

4. Murakawa K, Kobayashi A: Effects of vasopressors on renal tissue gas tensions during hemorrhagic shock in dogs. Crit Care Med 1988, 16:789-792.

5. Rosenberg AL, Dechert RE, Park PK, Bartlett RH: Review of a large clinical series: association of cumulative fluid balance on outcome in acute lung injury: a retrospective review of the ARDSnet tidal volume study cohort. J Intensive Care Med 2009, 24:35-46.

6. Murphy CV, Schramm GE, Doherty JA, Reichley RM, Gajic O, Afessa B, Micek ST, Kollef MH: The importance of fluid management in acute lung injury secondary to septic shock. Chest 2009, 136:102-109.

7. Boyd JH, Forbes J, Nakada T, Walley KR, Russell JA: Fluid resuscitation in septic shock: a positive fluid balance and elevated central venous pressure increase mortality. Crit Care Med 2010.

8. Tagami T, Kushimoto S, Yamamoto Y, Atsumi T, Tosa R, Matsuda K, Oyama R, Kawaguchi T, Masuno T, Hirama H, Yokota H: Validation of extravascular lung water measurement by single transpulmonary thermodilution: human autopsy study. Crit Care 2010, 14:R162.

9. Fernandez-Mondejar E, Rivera-Fernandez R, Garcia-Delgado M, Touma A, Machado J, Chavero J: Small increases in extravascular lung water are accurately detected by transpulmonary thermodilution. J Trauma 2005, 59:1420-1423

10. Monnet X, Anguel N, Osman D, Hamzaoui O, Richard C, Teboul JL: Assessing pulmonary permeability by transpulmonary thermodilution allows differentiation of hydrostatic pulmonary edema from ALI/ARDS. Intensive Care Med 2007, 33:448-453.

11. Sakka SG, Klein M, Reinhart K, Meier-Hellmann A: Prognostic value of extravascular lung water in critically ill patients. Chest 2002, 122:2080-2086.

12. Chung FT, Lin SM, Lin SY, Lin HC: Impact of extravascular lung water index on outcomes of severe sepsis patients in a medical intensive care unit. Respir Med 2008, 102:956-961.

13. Hayes MA, Timmins AC, Yau E, Palazzo M, Hinds CJ, Watson D: Elevation of systemic oxygen delivery in the treatment of critically ill patients. $N$ Engl J Med 1994, 330:1717-1722.

14. Gattinoni L, Brazzi L, Pelosi P, Latini R, Tognoni G, Pesenti A: A trial of goaloriented hemodynamic therapy in critically ill patients. N Engl J Med 1995, 333:1025-1032.

15. Marik PE, Cavallazzi R, Vasu T, Hirani A: Dynamic changes in arterial waveform derived variables and fluid responsiveness in mechanically ventilated patients. A systematic review of the literature. Crit Care Med 2009, 37:2642-2647.

16. Braunwald E, Sonnenblick EH, Ross J: Mechanisms of cardiac contraction and relaxation. In Heart Disease. Edited by: Braunwald E. Philadelphia: WB Saunders; 1988:383-425.

17. Nixon JV, Murray RG, Leonard PD, Mitchell JH, Blomqvist CG: Effect of large variations in preload on left ventricular characteristics in normal subjects. Circulation 1982, 65:698-703.

18. Kastrup M, Markewitz A, Spies C, Carl M, Erb J, Grosse J, Schirmer U: Current practice of hemodynamic monitoring and vasopressor and inotropic therapy in post-operative cardiac surgery patients in Germany: results from a postal survey. Acta Anaesthesiol Scand 2007, 51:347-358.

19. McIntyre LA, Hebert PC, Fergusson D, Cook DJ, Aziz A: A survey of Canadian intensivists' resuscitation practices in early septic shock. Crit Care 2007, 11:R74

20. Weil MH, Henning RJ: New concepts in the diagnosis and fluid treatment of circulatory shock. Thirteenth annual Becton, Dickinson and Company Oscar Schwidetsky Memorial Lecture. Anesth Analg 1979, 58:124-132.

21. Marik PE, Baram M, Vahid B: Does the central venous pressure predict fluid responsiveness? A systematic review of the literature and the tale of seven mares. Chest 2008, 134:172-178.

22. Nolen-Walston RD, Norton JL, de Solis C, Underwood C, Boston R, Slack J, Dallap BL: The effects of hypohydration on central venous pressure and splenic volume in adult horses. J Vet Intern Med 2010.

23. Magdesian KG, Fielding CL, Rhodes DM, Ruby RE: Changes in central venous pressure and blood lactate concentration in response to acute blood loss in horses. J Am Vet Med Assoc 2006, 229:1458-1462.
24. Michard F, Teboul JL: Using heart-lung interactions to assess fluid responsiveness during mechanical ventilation. Crit Care 2000, 4:282-289.

25. Theres H, Binkau J, Laule M, Heinze R, Hundertmark J, Blobner M, Erhardt W, Baumann G, Stangl K: Phase-related changes in right ventricular cardiac output under volume-controlled mechanical ventilation with positive end-expiratory pressure. Crit Care Med 1999, 27:953-958.

26. Desebbe O, Cannesson M: Using ventilation-induced plethysmographic variations to optimize patient fluid status. Curr Opin Anaesthesiol 2008, 21:772-778.

27. Natalini G, Rosano A, Taranto M, Faggian B, Vittorielli E, Bernaardini A: Arterial versus plethysmographic dynamic indices to test responsiveness for testing fluid administration in hypotensive patients: a clinical trial. Anesth Analg 2006, 103:1478-1484.

28. Cannesson M, Besnard C, Durand PG, Bohe J, Jacques D: Relation between respiratory variations in pulse oximetry plethysmographic waveform amplitude and arterial pulse pressure in ventilated patients. Crit Care 2005, 9:R562-R568.

29. Feissel M, Teboul JL, Merlani P, Badie J, Faller JP, Bendjelid K: Plethysmographic dynamic indices predict fluid responsiveness in septic ventilated patients. Intensive Care Med 2007, 33:993-999.

30. Cannesson M, Desebbe O, Rosamel P, Delannoy B, Robin J, Bastien O, Lehot JJ: Pleth variability index to monitor the respiratory variations in the pulse oximeter plethysmographic waveform amplitude and predict fluid responsiveness in the operating theatre. Br J Anaesth 2008, 101:200-206.

31. Cannesson M, Delannoy B, Morand A, Rosamel P, Attof Y, Bastien O, Lehot JJ: Does the Pleth variability index indicate the respiratoryinduced variation in the plethysmogram and arterial pressure waveforms? Anesth Analg 2008, 106:1189-1194.

32. Reuter DA, Bayerlein J, Goepfert MS, Weis FC, Kilger E, Lamm P, Goetz AE: Influence of tidal volume on left ventricular stroke volume variation measured by pulse contour analysis in mechanically ventilated patients. Intensive Care Med 2003, 29:476-480

33. De Backer D, Heenen S, Piagnerelli M, Koch M, Vincent JL: Pulse pressure variations to predict fluid responsiveness: influence of tidal volume. Intensive Care Med 2005, 31:517-523.

34. Feissel M, Michard F, Mangin I, Ruyer O, Faller JP, Teboul JL: Respiratory changes in aortic blood velocity as an indicator of fluid responsiveness in ventilated patients with septic shock. Chest 2001, 119:867-873.

35. Monnet X, Rienzo M, Osman D, Anguel N, Richard C, Pinsky MR, Teboul JL: Esophageal Doppler monitoring predicts fluid responsiveness in critically ill ventilated patients. Intensive Care Med 2005, 31:1195-1201.

36. Barbier C, Loubieres Y, Schmit C, Hayon J, Ricome JL, Jardin F, VieillardBaron A: Respiratory changes in inferior vena cava diameter are helpful in predicting fluid responsiveness in ventilated septic patients. Intensive Care Med 2004, 30:1740-1746.

37. Feissel M, Michard F, Faller JP, Teboul JL: The respiratory variation in inferior vena cava diameter as a guide to fluid therapy. Intensive Care Med 2004, 30:1834-1837.

38. Vieillard-Baron A, Augarde R, Prin S, Page B, Beauchet A, Jardin F: Influence of superior vena caval zone condition on cyclic changes in right ventricular outflow during respiratory support. Anesthesiol 2001 95:1083-1088.

39. Vieillard-Baron A, Chergui K, Rabiller A, Peyrouset O, Page B, Beauchet A, Jardin F: Superior vena caval collapsibility as a gauge of volume status in ventilated septic patients. Intensive Care Med 2004, 30:1734-1739.

40. Monnet X, Osman D, Ridel C, Lamia B, Richard C, Teboul JL: Predicting volume responsiveness by using the end-expiratory occlusion in mechanically ventilated intensive care unit patients. Crit Care Med 2009, 37:951-956.

41. Monnet X, Teboul JL: Passive leg raising. Intensive Care Med 2008, 34:659-663.

42. Teboul $J L$, Monnet $X$ : Prediction of volume responsiveness in critically ill patients with spontaneous breathing activity. Curr Opin Crit Care 2008, 14:334-339.

43. Monnet X, Rienzo M, Osman D, Anguel N, Richard C, Pinsky MR, Teboul L L Passive leg raising predicts fluid responsiveness in the critically ill. Crit Care Med 2006, 34:1402-1407.

44. Boulain T, Achard JM, Teboul JL, Richard C, Perrotin D, Ginies G: Changes in $\mathrm{BP}$ induced by passive leg raising predict response to fluid loading in critically ill patients. Chest 2002, 121:1245-1252. 
45. Lafanechere A, Pene F, Goulenok C, Delahaye A, Mallet V, Choukroun G, Chiche JD, Mira JP, Cariou A: Changes in aortic blood flow induced by passive leg raising predict fluid responsiveness in critically ill patients. Crit Care 2006, 10:R132.

46. Lamia B, Ochagavia A, Monnet X, Chemla D, Richard C, Teboul JL: Echocardiographic prediction of volume responsiveness in critically ill patients with spontaneously breathing activity. Intensive Care Med 2007, 33:1125-1132.

47. Maizel J, Airapetian N, Lorne E, Tribouilloy C, Massy Z, Slama M: Diagnosis of central hypovolemia by using passive leg raising. Intensive Care Med 2007, 33:1133-1138.

48. Biais M, Vidil L, Sarrabay P, Cottenceau V, Revel P, Sztark F: Changes in stroke volume induced by passive leg raising in spontaneously breathing patients: comparison between echocardiography and Vigileo/ FloTrac device. Crit Care 2009, 13:R195.

49. Thiel SW, Kollef MH, Isakow W: Non-invasive stroke volume measurement and passive leg raising predict volume responsiveness in medical ICU patients: an observational cohort study. Crit Care 2009, 13:R111.

50. Preau S, Saulnier F, Dewavrin F, Durocher A, Chagnon JL: Passive leg raising is predictive of fluid responsiveness in spontaneously breathing patients with severe sepsis or acute pancreatitis. Crit Care Med 2010, 38:819-825.

51. Cavallaro F, Sandroni C, Marano C, La TG, Mannocci A, De WC, Bello G, Maviglia R, Antonelli M: Diagnostic accuracy of passive leg raising for prediction of fluid responsiveness in adults: systematic review and meta-analysis of clinical studies. Intensive Care Med 2010, 36:1475-1483.

52. Lakhal K, Ehrmann S, Runge I, Benzekri Lefevre D, Legras A, Dequin PF, Mercier $\mathrm{E}$, Wolff $\mathrm{M}$ : Central venous pressure measurements improve the accuracy of leg raising-induced change in pulse pressure to predict fluid responsiveness. Intensive Care Med 2010, 36:940-948.

53. Monnet $X$, Teboul JL: Passive leg raising: keep it easy! Intensive Care Med 2010, 36:1445.

54. Mahjoub Y, Touzeau J, Airapetian N, Lorne E, Hijazi M, Zogheib E, Tinturier F, Slama M, Dupont H: The passive leg-raising maneuver cannot accurately predict fluid responsiveness in patients with intra-abdominal hypertension. Crit Care Med 2010, 38:1824-1829.

55. Keren H, Burkhoff D, Squara P: Evaluation of a noninvasive continuous cardiac output monitoring system based on thoracic bioreactance. Am J Physiol 2007, 293:H583-H589.

56. Raval NY, Squara P, Cleman M, Yalamanchili K, Winklmaier M, Burkhoff D: Multicenter evaluation of noninvasive cardiac output measurement by bioreactance technique. J Clin Monitor Comput 2008, 22:113-119.

57. Squara P, Rotcajg D, Denjean D, Estagnasie P, Brusset A: Comparison of monitoring performance of Bioreactance vs. pulse contour during lung recruitment maneuvers. Crit Care 2009, 13:R125.

58. Benomar B, Ouattara A, Estagnasie P, Brusset A, Squara PP: Fluid responsiveness predicted by noninvasive bioreactance-based passive leg raise test. Intensive Care Med 2010, 36:1875-1881.

59. Keller G, Cassar E, Desebbe O, Lehot JJ, Cannesson M: Ability of pleth variability index to detect hemodynamic changes induced by passive leg raising in spontaneously breathing volunteers. Crit Care 2008, 12:R37.

doi:10.1186/2110-5820-1-1

Cite this article as: Marik et al:: Hemodynamic parameters to guide fluid therapy. Annals of Intensive Care 2011 1:1.

\section{Submit your manuscript to a SpringerOpen ${ }^{\mathcal{O}}$ journal and benefit from:}

- Convenient online submission

- Rigorous peer review

- Immediate publication on acceptance

- Open access: articles freely available online

- High visibility within the field

- Retaining the copyright to your article

Submit your next manuscript at $\gg$ springeropen.com 